University of Windsor

Scholarship at UWindsor

2010

\title{
A quantitative description of the vocalizations and vocal activity of the Barred Owl
}

Karan J. Odom

Daniel J. Mennill

University of Windsor

Follow this and additional works at: https://scholar.uwindsor.ca/biologypub

Part of the Biology Commons

\section{Recommended Citation}

Odom, Karan J. and Mennill, Daniel J., "A quantitative description of the vocalizations and vocal activity of the Barred Owl" (2010). Condor, 112, 3, 549-560.

https://scholar.uwindsor.ca/biologypub/1028

This Article is brought to you for free and open access by the Department of Biological Sciences at Scholarship at UWindsor. It has been accepted for inclusion in Biological Sciences Publications by an authorized administrator of Scholarship at UWindsor. For more information, please contact scholarship@uwindsor.ca. 


\section{A Quantitative Description of the Vocalizations and Vocal Activity of the Barred Owl}

Author(s): Karan J. Odom and Daniel J. Mennill

Source: The Condor, 112(3):549-560.

Published By: Cooper Ornithological Society

URL: http://www.bioone.org/doi/full/10.1525/cond.2010.090163

BioOne (www.bioone.org) is a nonprofit, online aggregation of core research in the biological, ecological, and environmental sciences. BioOne provides a sustainable online platform for over 170 journals and books published by nonprofit societies, associations, museums, institutions, and presses.

Your use of this PDF, the BioOne Web site, and all posted and associated content indicates your acceptance of BioOne's Terms of Use, available at www.bioone.org/page/terms of use.

Usage of BioOne content is strictly limited to personal, educational, and non-commercial use. Commercial inquiries or rights and permissions requests should be directed to the individual publisher as copyright holder. 


\title{
A QUANTITATIVE DESCRIPTION OF THE VOCALIZATIONS AND VOCAL ACTIVITY OF THE BARRED OWL
}

\author{
Karan J. Odom ${ }^{1}$ and Daniel J. Mennill
}

Department of Biological Sciences, University of Windsor, Windsor, Ontario N9B3P4, Canada

\begin{abstract}
Barred Owls (Strix varia) are highly vocal and perform a diverse array of vocalizations. They are often monitored by acoustic surveys, yet Barred Owl vocalizations and vocal behavior are poorly described. We present a detailed analysis of Barred Owl vocal behavior with four goals: (1) to provide a quantitative description of Barred Owl vocalizations, including those given within duets, (2) to examine diel variation in vocal output for multiple vocalizations, (3) to explore the use of vocalizations inside and outside of duets, and (4) to identify sexspecific vocal characteristics and discuss their utility in identifying an owl's sex. Adult Barred Owls produced 13 distinct vocalizations that could be assigned to call type on the basis of fine-structural measurements. Barred Owls vocalized throughout the day but were more vocal at night with peaks in vocal activity from 18:00 to 20:00 and 02:00 to 05:00. Most calls were produced throughout the night, but some (e.g., alarm calls) were more common at particular times. Two types of vocalizations were produced only within duets, and one type of vocalization occurred primarily outside duets. Calls of females were higher in pitch with longer terminal notes and more vibrato than those of males. Using these differences, cluster analysis assigned owls to two groups corresponding to predicted sex with $91 \%$ accuracy. We discuss possible functions of certain vocalizations and how understanding the vocal repertoire and sex differences of this species' acoustic signals will benefit behavioral studies and monitoring, including Spotted Owl (Strix occidentalis) conservation.
\end{abstract}

Key words: Barred Owl, behavior, duet, Strix varia, vocalizations.

\section{Una Descripción Cuantitativa de las Vocalizaciones y la Actividad Vocal de Strix varia}

Resumen. Strix varia es altamente vocal y emite un espectro diverso de vocalizaciones. Con frecuencia, estas aves son monitoreadas mediante censos acústicos, pero sus vocalizaciones y comportamiento vocal están descritos pobremente. Presentamos un análisis detallado del comportamiento vocal de $S$. varia con cuatro objetivos: (1) describir las vocalizaciones de la especie cuantitativamente, incluyendo aquellas emitidas en duetos, (2) examinar la variación a lo largo del día en la producción de múltiples vocalizaciones, (3) explorar el uso de vocalizaciones en duetos y fuera de éstos, y (4) identificar características vocales específicas de cada sexo y discutir su utilidad para determinar el sexo de los individuos. Categorizamos las vocalizaciones de individuos adultos en 13 tipos de llamadas con base en su estructura fina. Los individuos vocalizaron durante todo el día pero lo hicieron con mayor frecuencia en la noche, con picos en la actividad vocal de las 18:00 a las 20:00 y de las 02:00 a las 05:00. La mayoría de llamadas fueron emitidas durante toda la noche, pero algunas (e.g., las de alarma) fueron más comunes a horas particulares. Dos tipos de vocalizaciones fueron producidas sólo como parte de duetos y un tipo de vocalización se emitió primordialmente fuera de los duetos. Las llamadas de las hembras presentaron frecuencias mayores, notas terminales más largas y más vibrato que las de los machos. Con base en esas diferencias, nuestros análisis de conglomerados asignaron a los individuos a dos grupos correspondientes a los sexos predichos con una exactitud del $91 \%$. Discutimos las posibles funciones de algunas vocalizaciones y explicamos cómo entender el repertorio vocal y las diferencias entre sexos en las señales acústicas de esta especie beneficiará a los estudios de comportamiento y monitoreo, incluyendo la conservación de Strix occidentalis.

\section{INTRODUCTION}

Barred Owls (Strix varia) are very vocal animals, with one of the most diverse vocal repertoires among North American owls (Eckert 1974). They are abundant throughout the eastern United States and Canada, with rapidly increasing numbers in the Pacific Northwest (Mazur and James 2000, Gutiérrez et al.
2007). The Barred Owl has been used as an indicator species in several national forests (e.g., U.S. Department of Agriculture $1985,1986,1987)$ and has become a species of interest to conservation biologists because it is expanding its range into the current range of the Spotted Owl (Strix occidentalis), designated as threatened by the U.S. Fish and Wildlife Service (Buchanan et al. 2007). Barred Owls are nocturnal, and

Manuscript received 24 August 2009; accepted 15 March 2010.

${ }^{1}$ E-mail: kjodom@gmail.com

The Condor, Vol. 112, Number 3, pages 549-560. ISSN 0010-5422, electronic ISSN 1938-5422. @ 2010 by The Cooper Ornithological Society. All rights reserved. Please direct all requests for permission to photocopy or reproduce article content through the University of California Press's Rights and Permissions website, http://www.ucpressjournals.com/ reprintInfo.asp. DOI: 10.1525/cond.2010.090163 
vocalizations play an important role in their communication, behavior, and biology (Galeotti and Pavan 1991). Multiple studies have highlighted the usefulness of vocal surveys for detecting this species (McGarigal and Fraser 1985, Mosher et al. 1990, Crozier et al. 2006). Understanding the Barred Owl's vocalizations and natural diel variation in its vocal output will be helpful for future research on this widely distributed species. This includes conservation and management efforts, such as survey procedures, protocols for playback, and passive monitoring.

Several accounts of the Barred Owl vocal repertoire exist but are anecdotal, do not provide consistent nomenclature for the call types described, and lack information on behavioral context and differences between the sexes (Brewster and Chapman 1891, Bent 1938, Eckert 1974, Johnsgard 1988, Mazur and James 2000). Bent (1938) provided the most thorough account, describing 11 types of vocalizations as well as duets, but the absence of consistent nomenclature makes his descriptions difficult to use and inaccessible to anyone unfamiliar with this species' calls. All published accounts treat the Barred Owl's complex vocal duets (commonly referred to as "caterwaul bouts," Mazur and James 2000) as a single vocalization. These duets, however, are a complex combination of vocalizations performed by a breeding pair. Very few studies have looked at calling behavior, and no studies to date have examined diel variation in calling patterns (McGarigal and Fraser 1985, Dunstan and Sample 1972, Mazur and James 2000). McGarigal and Fraser (1985) and Bird and Wright (1991) provided information on the context of vocalizations but focused on only a few call types. Several accounts describe the female Barred Owl's calls as higher-pitched than the male's (Bent 1938, Johnsgard 1988, Bird and Wright 1991). In addition, Kroodsma (2005) suggested that male and female vocalizations also differ in length and amount of vibrato (frequency modulations) in the terminal note of the call. However, consistency in these differences and their usefulness for assigning sex have not been evaluated.

In this study, we provide a detailed description of the vocalizations and vocal behavior of the Barred Owl. Our study has four main goals: (1) to provide a full, quantitative description of all vocalizations the species produces, including vocalizations performed within duets, (2) to describe diel variation in call output for the different vocalizations, (3) to understand differences in how Barred Owls use these vocalization inside and outside of duets, and (4) to quantify the described differences between male and female vocalizations and examine whether these differences might be useful for distinguishing between owls of unknown sex.

\section{METHODS}

We recorded Barred Owls of both known and unknown sex. Individuals of known sex were captive birds recorded at wildlife-rehabilitation facilities in central Florida in March 2004 and March and August 2005. Individuals of unknown sex were recorded in the wild at 26 locations along the Choctawhatchee River in Washington and Holmes counties in northwestern Florida from January to May 2007 and January to February 2008. Each location was separated by at least $500 \mathrm{~m}$ from all other locations. We considered a separation of $500 \mathrm{~m}$ to be adequate for sampling different pairs of owls, on the basis of hearing two to three pairs of Barred Owls from a single location and radio-telemetry studies indicating that other southeastern populations maintain contiguous territories averaging $200 \mathrm{~m}$ in diameter (R. Bierregaard Jr., pers. comm.). Captive Barred Owls were housed individually but often in vocal contact with one or more conspecifics. All captive owls that we recorded were healthy residents at state-permitted rehabilitation facilities and zoos, having sustained permanent injuries that precluded their release.

We recorded calls of wild owls during spontaneous bouts of calling or by using standardized playback to elicit vocalizations. The playback we used to elicit calling consisted of three tracks of common vocalizations: (1) single-note calls given by each a male and female, (2) eight two-phrased hoots (Mazur and James 2000) given by a male and female in alternation, (3) ascending hoots (Mazur and James 2000) given by both males and females. We used a 13 -sec duet as a fourth track in early trials, but we eliminated that track early in the 2007 field season. The first and fourth tracks were created from recordings of Barred Owls from central Florida provided by Cornell Lab of Ornithology's Macaulay Library of Natural Sounds. The second and third tracks were created from two mated pairs of wild owls we recorded in north Florida. We played the tracks in the order numbered above with 5 min of silence between each playback. Track 3 was played up to three times if no owls responded to the first three tracks. Once owls responded vocally, we ceased playback immediately and recorded the birds' vocalizations. Captive owls were recorded during spontaneous bouts of calling, after human imitation of Barred Owl vocalizations by caregivers, or in response to the above standardized playback.

\section{SOUND RECORDING AND ANALYSIS}

Captive owls were recorded with a Sony TC-D5 Pro II tape recorder and an Audiotechnica AT835 microphone. Wild owls were recorded both focally and with passive automated recording devices. Focal recordings were made with a Marantz PMD-670 solid-state digital recorder and a Sennhieser ME-67/K6 shotgun microphone. Automated recordings were made with a Marantz PMD-670 digital recorder powered by a sealed lead-acid battery and a Sennheiser ME-62/K6 omnidirectional microphone. Microphones for automated recording devices were mounted on shelf brackets attached to 3-m wooden posts that we attached to small trees. Sounds were recorded as MP3 files on a Hitachi 3GB microdrive at a sampling frequency of $44.1 \mathrm{kHz}$ and a bit rate of $160 \mathrm{~kb} \mathrm{sec}^{-1}$. 
TABLE 1. Barred Owl vocalizations and average ( $\pm \mathrm{SE})$ fine-structural measurements for females and males.

\begin{tabular}{|c|c|c|c|c|c|c|c|c|}
\hline Call type & $\begin{array}{l}\text { Predicted } \\
\text { sex }\end{array}$ & $n$ & $\begin{array}{l}\text { Call duration } \\
\qquad(\mathrm{sec})\end{array}$ & $\begin{array}{c}\text { Mean } \\
\text { no. notes }\end{array}$ & $\begin{array}{l}\text { Duration } \\
\text { terminal } \\
\text { note }(\mathrm{sec})\end{array}$ & $F_{\max }(\mathrm{Hz})$ & FMA (Hz) & $\begin{array}{c}\text { No. } \\
\text { inflection } \\
\text { points }\end{array}$ \\
\hline Inspection call & $\mathrm{F}$ & 17 & $1.20 \pm 0.05$ & $1.00 \pm 0.00$ & $1.20 \pm 0.05$ & $639 \pm 6$ & $585 \pm 19$ & $11.1 \pm 1.6$ \\
\hline Inspection call & M & 20 & $0.73 \pm 0.03$ & $1.00 \pm 0.00$ & $0.72 \pm 0.03$ & $589 \pm 10$ & $511 \pm 23$ & $5.1 \pm 1.1$ \\
\hline Two-phrase hoot & $\mathrm{F}$ & 22 & $3.40 \pm 0.08$ & $8.00 \pm 0.00$ & $0.79 \pm 0.03$ & $618 \pm 7$ & $573 \pm 14$ & $11.2 \pm 1.1$ \\
\hline Two-phrase hoot & $\mathrm{M}$ & 23 & $2.98 \pm 0.06$ & $7.96 \pm 0.08$ & $0.38 \pm 0.02$ & $537 \pm 10$ & $481 \pm 20$ & $2.9 \pm 0.7$ \\
\hline One-phrase hoot & $\mathrm{F}$ & 18 & $2.10 \pm 0.10$ & $4.00 \pm 0.00$ & $0.76 \pm 0.05$ & $591 \pm 13$ & $515 \pm 24$ & $11.7 \pm 1.4$ \\
\hline One-phrase hoot & $\mathrm{M}$ & 13 & $1.53 \pm 0.09$ & $4.15 \pm 0.15$ & $0.43 \pm 0.03$ & $518 \pm 22$ & $423 \pm 31$ & $3.9 \pm 0.9$ \\
\hline Ascending hoot & $\mathrm{F}$ & 12 & $3.61 \pm 0.15$ & $8.67 \pm 0.43$ & $0.83 \pm 0.04$ & $593 \pm 13$ & $519 \pm 18$ & $14.6 \pm 1.3$ \\
\hline Ascending hoot & M & 18 & $2.92 \pm 0.14$ & $8.56 \pm 0.41$ & $0.44 \pm 0.02$ & $506 \pm 16$ & $491 \pm 11$ & $5.1 \pm 0.8$ \\
\hline $\begin{array}{l}\text { Short ascending } \\
\text { hoot }\end{array}$ & $\mathrm{F}$ & 13 & $2.40 \pm 0.11$ & $5.08 \pm 0.14$ & $0.78 \pm 0.05$ & $607 \pm 11$ & $493 \pm 34$ & $15.1 \pm 2.1$ \\
\hline $\begin{array}{l}\text { Short ascending } \\
\text { hoot }\end{array}$ & M & 12 & $1.89 \pm 0.08$ & $5.50 \pm 0.23$ & $0.38 \pm 0.03$ & $495 \pm 21$ & $401 \pm 32$ & $4.2 \pm 1.2$ \\
\hline Fast ascent & $\mathrm{F}$ & 4 & $2.91 \pm 0.11$ & $9.00 \pm 0.71$ & $0.53 \pm 0.04$ & $561 \pm 32$ & $442 \pm 61$ & $8.0 \pm 1.1$ \\
\hline Fast ascent & M & 12 & $2.78 \pm 0.26$ & $9.17 \pm 0.84$ & $0.40 \pm 0.02$ & $520 \pm 17$ & $465 \pm 28$ & $4.3 \pm 0.9$ \\
\hline Gurgle & $\mathrm{F}$ & 2 & $2.04 \pm 0.64$ & $5.50 \pm 0.50$ & $0.70 \pm 0.28$ & $551 \pm 14$ & $325 \pm 38$ & $12.5 \pm 10.5$ \\
\hline Gurgle & M & 18 & $1.94 \pm 0.08$ & $6.39 \pm 0.30$ & $0.33 \pm 0.03$ & $613 \pm 55$ & $518 \pm 51$ & $2.4 \pm 0.8$ \\
\hline Two-note & $\mathrm{F}$ & 5 & $0.96 \pm 0.11$ & $2.00 \pm 0.00$ & $0.62 \pm 0.09$ & $627 \pm 15$ & $595 \pm 22$ & $6.6 \pm 2.7$ \\
\hline Two-note & $\mathrm{M}$ & 3 & $0.79 \pm 0.05$ & $2.00 \pm 0.00$ & $0.44 \pm 0.04$ & $655 \pm 164$ & $470 \pm 31$ & $6.3 \pm 2.3$ \\
\hline Three-note & $\mathrm{F}$ & 1 & 1.06 & 3.00 & 0.57 & 543 & 508 & 13.0 \\
\hline Three-note & $\mathrm{M}$ & 5 & $0.92 \pm 0.07$ & $3.00 \pm 0.00$ & $0.39 \pm 0.04$ & $549 \pm 30$ & $436 \pm 54$ & $5.0 \pm 1.7$ \\
\hline Mumble & $\mathrm{F}$ & 2 & $1.35 \pm 0.17$ & $3.00 \pm 0.00$ & $0.80 \pm 0.06$ & $606 \pm 7$ & $589 \pm 1$ & $12.0 \pm 4.0$ \\
\hline Mumble & $\mathrm{M}$ & 6 & $0.83 \pm 0.08$ & $3.00 \pm 0.00$ & $0.30 \pm 0.04$ & $423 \pm 61$ & $417 \pm 51$ & $2.0 \pm 1.0$ \\
\hline Twitter & M & 4 & $1.19 \pm 0.15$ & $7.25 \pm 1.11$ & $0.04 \pm 0.01$ & $4121 \pm 637$ & $3230 \pm 116$ & $0.0 \pm 0.0$ \\
\hline Female begging & $\mathrm{F}$ & 5 & $1.32 \pm 0.15$ & $1.00 \pm 0.00$ & $1.32 \pm 0.15$ & $828 \pm 23$ & $802 \pm 32$ & $0.0 \pm 0.0$ \\
\hline $\begin{array}{l}\text { Scream } \\
\quad(\text { alarm call })\end{array}$ & $\mathrm{F}$ & 13 & $2.63 \pm 0.48$ & $1.46 \pm 0.24$ & $1.91 \pm 0.14$ & $1056 \pm 89$ & $896 \pm 25$ & $0.0 \pm 0.0$ \\
\hline
\end{tabular}

Full details of the automated recording devices can be found in Hill et al. (2006). Focal recordings were recorded as WAV files as described above. We used the program Cool Edit 2000 (Syntrillium Software Corp. 2002) to digitize taped recordings from 2004 and 2005 at a sampling frequency of $16 \mathrm{kHz}$.

We used Syrinx-PC (Burt 2006) to visualize sounds as spectrograms. We isolated vocalizations from focal and automated recordings to create separate data sets for analyzing Barred Owl vocalizations, diel variation in vocal output, and vocal activity in and outside of duets. We used the same data set to describe vocalizations quantitatively and for exploring possible differences between male and female vocalizations. We made fine-scale measurements by using Audition 2.0 (Adobe Systems, Inc. 2005) with settings as follows: Blackman-Harris window function; resolution $512 \mathrm{~Hz}$; window width $100 \%$. These settings provided an effective time resolution of $1 \mathrm{msec}$ and effective frequency resolution of $22 \mathrm{~Hz}$.

Quantitative description of vocalizations. Using recordings of captive individuals of known sex, we categorized vocalizations into a repertoire of call types based on structural differences, including number of notes, differences in note length, interval between notes, maximum frequency, and bandwidth. We compared this repertoire with observations in the field from 2007 and 2008. In the field, we heard several vocalizations that we did not record from the captive birds, and we added these vocalization types to the repertoire. Using this repertoire as a guide, we attempted to isolate two clear examples of each type of vocalization from each of the 26 locations where we recorded in 2007 and 2008, targeting one example from a predicted male and one from a predicted female (see below). We could not find high-quality recordings of all vocalizations from every location, but we collected at least ten (and a maximum of 23) well-recorded examples of common vocalization types from each predicted sex. For a few call types, it was difficult to obtain clear recordings because they were typically produced as part of a duet and were usually overlapped by the mate's calls. We obtained as many good recordings of these less common vocalizations as possible (Table 1 identifies the final sample size for each type of vocalization).

Ten variables were measured for each example of each call. Measurements were designed to provide information about overall characteristics of the call, as well as parameters expected to distinguish males from females based on Kroodsma's (2005) description. These variables were: (1) call duration, (2) number of notes, (3) duration of the terminal note, (4) frequency of maximum amplitude (FMA) for the entire call, (5) duration from the point of FMA to the end of the call, (6) FMA of the terminal note, (7) duration from the point of FMA of the terminal note to the end of the call, (8) maximum frequency $\left(F_{\max }\right)$ of the terminal note, $(9)$ duration from $F_{\text {max }}$ of 
the terminal note to the end of the call, and (10) number of inflection points in the terminal note. We defined notes as structures that were separated by a silent interval, however brief, in the sound spectrogram. We counted inflection points as each mid-point of a downward or upward slope within frequency modulations. Because of our interest in potential sex differences, we focused on inflection points within the rapid modulations at the ends of terminal notes, which Kroodsma (2005) suggested may help distinguish between the sexes. Several call types previously described as distinct were noticeably different from all others, solely on the basis of hearing without the aid of spectrographs for categorization; we considered these obvious vocalization types distinct and did not analyze them further. Several other vocalizations were quite similar to each other, so we performed canonical discriminant function analysis to determine if they could be separated into distinct vocalization types.

Diel variation and vocal behavior. To examine diel variation in Barred Owl vocalizations and to quantify use of vocalizations within duets and outside of duets, we scanned 24-hr recordings from automated recording devices. For the analysis of diel variation, we used one recording from each of 12 different locations, each recorded on a different day from early January to mid-February 2007. This interval corresponds to the period just prior to the Barred Owl's breeding season in north Florida and a time of year when Barred Owls are highly vocal. We determined the time and type of each vocalization produced within the entire $24 \mathrm{hr}$ for each of the 12 recordings. Duets were treated as a single vocalization for this analysis because the overlapping vocalizations of distant birds made it challenging to classify calls beyond this level. We calculated the average $( \pm \mathrm{SE})$ output for each vocalization for each hour over $24 \mathrm{hr}$. We used a linear mixed-model ANOVA to analyze diel variation in call rates for all vocalizations combined to determine if vocal activity varied significantly with time of day. We evaluated diel variation in call rates of seven common solo vocalizations and duets purely on a descriptive basis to avoid reduced power from multiple statistical comparisons and because of low occurrence of certain vocalization types during many hours of the day.

We also examined the prevalence of particular vocalizations inside and outside of Barred Owl duets. We counted the number of each type of vocalization and the total number of calls that occurred in each duet for 25 duets. Each duet was recorded from a different pair of owls isolated from automated and focal recordings at separate recording locations from 2007 and 2008. To create a comparison dataset for solo calls (calls produced outside the context of duets), we isolated the same number of solo calls from each recording to match the number of calls within the duet. Starting at midnight, we tallied calls until the necessary number of solo calls was reached, then calculated how often each of the vocalization types occurred.
Male-female differences. To confirm Kroodsma's (2005) and our own observed differences in male and female vocalizations, we made two comparisons of male and female vocalizations, one using recordings of individuals of known sex and one using recordings of wild owls of unknown sex. For the captive owls of known sex, we compared means $( \pm S E)$ for $F_{\max }$ of the terminal note, duration of terminal note, and number of inflection points in the terminal note. We measured one vocalization of one common call type, the two-phrased hoot, from each individual. Because the sample of captive owls was small (two males, four females), we did not analyze these data statistically but used descriptive measurements to evaluate whether their vocal characteristics corresponded to sex.

Female Barred Owls are already known to produce vocalizations that are higher-pitched than those of males (Mazur and James 2000) and have been identified previously solely on the basis of this criterion (Bird and Wright 1991); we were particularly interested in evaluating whether the higherfrequency calls also had longer terminal notes with increased vibrato. We investigated whether our recordings of wild owls of unknown sex could be readily separated into two groups by auditory cues and measurements that can be taken from sound spectrograms. To do this, we separated calls recorded from owls of unknown sex into a group of predicted males and a group of predicted females; classification was qualitative, based on auditory and visual (spectrogram-based) assessment of pitch, as well as the amount of vibrato and duration of the terminal note. We then used cluster analysis to determine if these calls from owls of unknown sex could be quantitatively assigned to two groups on the basis of fine-structural measurements and whether these quantitative assignments corresponded to our qualitative assessments. We measured the same 10 fine-structural variables for the vocalizations that we qualitatively grouped into predicted males and females, and conducted cluster analysis using these data. This cluster analysis assigned wild owls into two groups (clusters) on the basis of fine-structural features alone, without our designating presumed sex.

In our recordings of wild owls, we observed that duets were always composed of vocalizations by an owl with lowerpitched calls and truncated terminal notes and a second owl with higher-pitched calls with a longer terminal note and more vibrato; from our own experience and previous observations (Kroodsma 2005) we presumed the former was a male and the latter was a female. One-third of recordings used in this analysis were from focal recordings of a pair of owls either duetting or seen together at the time of recording. This increased our confidence that we were recording mated pairs and focusing on male-female differences. All other recordings were gathered from automated recording devices deployed in active Barred Owl territories. We analyzed only one vocalization type from each predicted sex per automated recording location. Fine-structural details of the different call types 
(means $\pm \mathrm{SE}$ ) are presented in the text as averages with the sexes pooled, but the average value for each sex is presented separately in Table 1.

\section{STATISTICAL ANALYSES}

Using a cross-validation technique, we performed canonical discriminant function analysis on the fine-structural measurements of the six common vocalizations. We randomly selected $80 \%$ of the data, constructed the canonical discriminant analysis, and then evaluated our ability to classify the call type correctly in the remaining $20 \%$ of the data. We report eigenvectors and canonical scores for the $80 \%$ of the data on which the discriminant function was based, and we report accuracy as the percentage of the $20 \%$ of the data tested by crossvalidation. We considered canonical vectors with eigenvalues greater than 1.0 to contribute significantly to differentiation between vocalization types. We used variables with correlation coefficients greater than \pm 0.5 to explain the variation described by canonical vectors.

To evaluate diel variation in call output for all vocalizations combined, we used a linear mixed-model ANOVA with a repeated-measures design. We chose this method instead of a general linear model repeated-measures ANOVA because the latter eliminates cases (in our study, automated recording locations) with missing values. At three recording locations $1 \mathrm{hr}$ of the 24-hr period was missing because the recording finished early when the battery was exhausted. The model was constructed with call occurrence as the dependent variable, hour as a fixed factor, and each automated recording location as a repeated measure. We ran the model on the covariance matrix, and an unstructured model was specified.

To compare the occurrence of calls inside and outside of duets, we used log-linear regression, run as a three-way repeated-measures ANOVA. We used an expanded data set of presence or absence, with each row representing a single vocalization within a duet. In our model, the within-subjects factor was vocalization type, and the between-subjects factor was whether the vocalization occurred within a duet or outside of a duet (i.e., as a solo). We evaluated the results on the basis of interaction of vocalization type and in or outside of a duet.

For our cluster analysis of sex differences using finestructural measurements, we used hierarchical cluster analysis with Ward's method with two clusters specified to construct a phenogram based on all fine-structural measurements. We created the phenogram from the six common vocalization types (184 calls in total, including 98 predicted males and 86 predicted females). We calculated correct assignment as the percentage of predicted males and females assigned to distinct, singly rooted clusters.

Canonical discriminant function analysis and cluster analysis were performed in JMP 5.0 (SAS Institute 2002). All other analyses were performed in SPSS 17.0 (SPSS Inc. 2008). All descriptive statistics are presented as mean \pm SE.

\section{RESULTS}

\section{QUANTITATIVE DESCRIPTION OF VOCALIZATIONS}

Description of vocal repertoire. Adult Barred Owls performed 13 types of vocalizations and one nonvocal sound (Fig. 1, Table 1). Table 1 describes the fine-structural properties of each type of vocalization.

Inspection call (Fig. 1A). This call is a single, loud, long note $(0.97 \pm 0.04 \mathrm{sec})$ with a slight rise in pitch (FMA: $548 \pm 21 \mathrm{~Hz}$; $F_{\max }: 613 \pm 8 \mathrm{~Hz}$ ) followed by a rapid descent: hooooahh.

Two-phrased hoot (Fig. 1B). This call consists of two sets of four syncopated notes, three short and one long (total duration: $3.19 \pm 0.07 \mathrm{sec}$ ). The terminal note of the second phrase is the longest note $(0.58 \pm 0.03 \mathrm{sec}$; nearly $20 \%$ of the call $)$ and is the typical terminal note within most Barred Owl calls: a quick upward frequency sweep of 300-500 Hz followed by a rapid, heavily accented descending sweep, connected by a steady rise in pitch. The entire call is known by the popular mnemonic, who cooks for you? who cooks for you all? and is sometimes referred to as the "cook call" (Bent 1938, Freeman 2000).

One-phrased hoot (Fig. 1C). This call is made up of 4.07 \pm 0.07 notes and is similar to the second phrase of the twophrased hoot but can be truncated like the first phrase (total duration: $1.82 \pm 0.10 \mathrm{sec}$ ). Females often give a drawn-out, evenly accented version in duets or following an alarm call.

Ascending hoot (Fig. 1D). On average, this call has 8.62 \pm 0.42 evenly spaced notes, but it can be longer. It lasts 3.27 $\pm 0.15 \mathrm{sec}$ and steadily increases in pitch and amplitude. The terminal note is long $(0.64 \pm 0.06 \mathrm{sec} ; 20 \%$ of the call $)$ and typical of the species. The penultimate and terminal notes are in quick succession and strongly accented: hoo-hoo-hoohoo-hoo-hoo-HO-WAH. Also referred to as the "legato hoot" (Freeman 2000).

Short ascending hoot (Fig. 1E). This call is similar to the ascending hoot, with an even progression of ascending notes, ending with the species-typical terminal note. However, it has only $5.29 \pm 0.19$ syllables and is shorter $(2.15 \pm 0.10 \mathrm{sec})$ than the ascending hoot. We distinguished short ascending hoots from ascending hoots because short ascending hoots appeared to be more often associated with duets.

Fast ascent (Fig. 1F). This series of evenly spaced notes ascends rapidly to a species-typical terminal note. It is similar to the ascending hoot but has a slightly shorter duration (2.84 \pm $0.019 \mathrm{sec}$ ) yet one to two more notes on average than the ascending hoot (Table 1). The lengths of the notes and the intervals between them are shorter, making the call sound hurried.

Gurgle (Fig. 1G). This call consists of $5.95 \pm 0.04$ hollow, throaty notes (total duration is $1.99 \pm 0.36 \mathrm{sec}$ ) visually distinguished by harmonic stacking with frequency components higher than those of other, similar Barred Owl calls. The pattern of the gurgle call is variable but most similar to the ascending hoot. The terminal note of the call can be short $(0.52 \pm 0.16 \mathrm{sec})$. In combination, the last two notes create an abrupt up and 

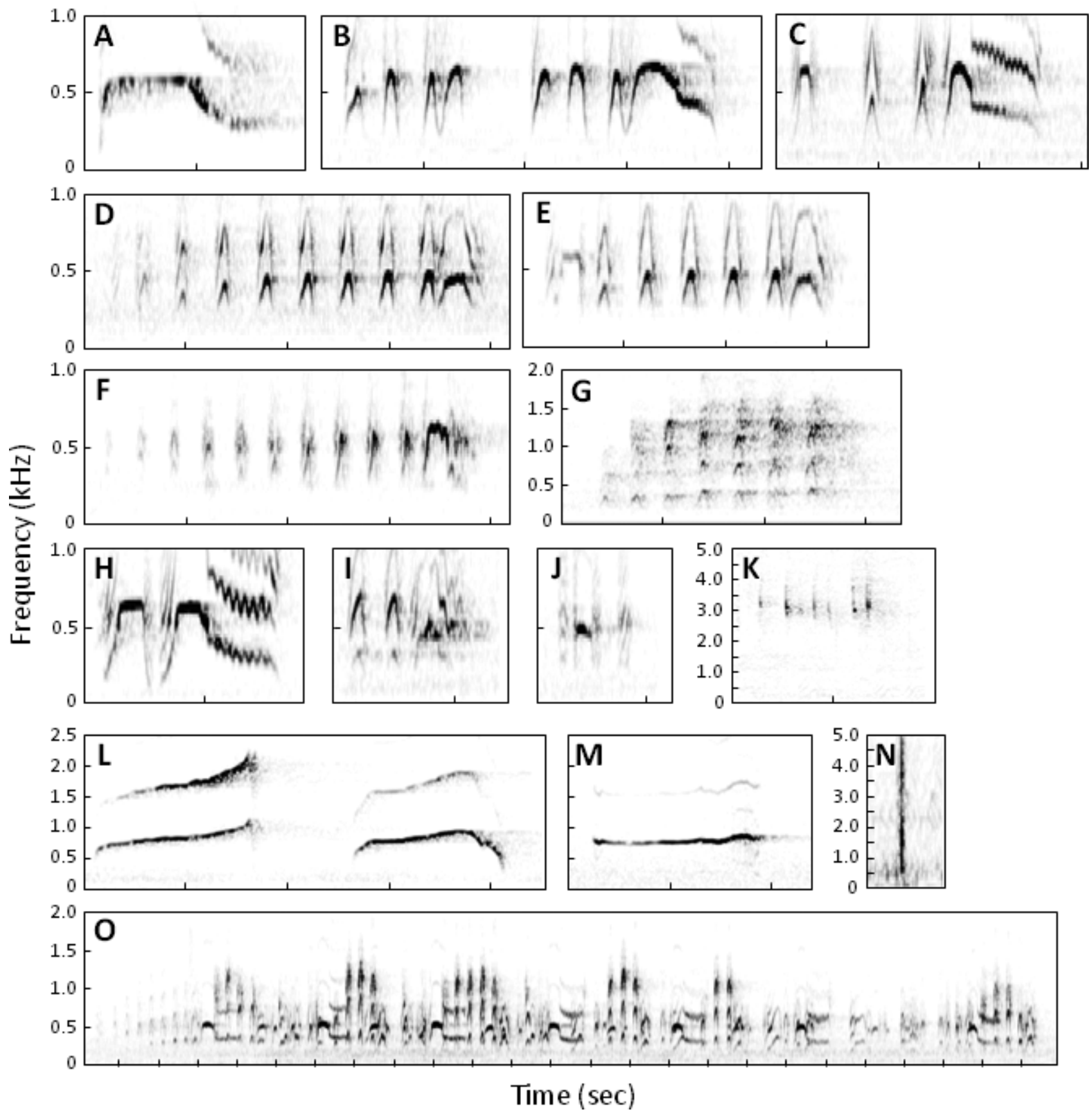

FIGURE 1. Spectrographs showing 13 vocalizations, one nonvocal sound, and a duet recorded from wild Barred Owls: (A) inspection call, (B) two-phrased hoot, (C) one-phrased hoot, (D) ascending hoot, (E) short ascending hoot, (F) fast ascent, (G) gurgle, (H) two-note, (I) three-note, (J) mumble, (K) twitter, (L) scream (alarm call), (M) female begging, (N) bill snap, and (O) duet. The time scale is standardized so that one tick equals one second.

down inflection, similar to the double-note $u h$-uh call of a Fish Crow (Corvus ossifragus; McGowan 2001). The entire call has been described as "maniacal" or a "deep chuckling" (Eckert 1974).

Two-note (Fig. 1H). Both notes in this two-note call are heavily accented. The total duration is short $(0.87 \pm 0.08 \mathrm{sec})$, but the first note is longer than most beginning notes of other calls. The second note is longer than the first $(0.53 \pm 0.07 \mathrm{sec}$; $61 \%$ of the call) and species-typical but with a prolonged descent: hooo-HOOOAAAH.

Three-note (Fig. 1I). The three-note call consists of three distinct, evenly spaced notes performed on approximately the 
same pitch. The species-typical terminal note $(0.48 \pm 0.04$ sec) makes up $40-54 \%$ of the total duration $(1.01 \pm 0.07 \mathrm{sec})$. The first two notes are similar in length to one another, and either or both may be heavily accented with intensity equal to the terminal note: $\mathrm{HOO}-\mathrm{HOO}-\mathrm{HOOOO}$.

Mumble (Fig. 1J). This is a short call $(1.09 \pm 0.12 \mathrm{sec})$ with three low notes. The middle note is higher-pitched and may be longer than the first and third notes. The terminal note $(0.55 \pm$ $0.05 \mathrm{sec}$ ) constitutes up to $50 \%$ of the total duration, but it can be shorter and is not accented like species-typical terminal notes. All three notes are quick and indistinct: err-ERR-err.

Twitter (Fig. 1K). This series of variable-pitched, squeaky notes $(7.25 \pm 1.11 \mathrm{sec})$ is high-pitched with a broad bandwidth $\left(F_{\min }: 2666 \pm 337 \mathrm{~Hz} ; F_{\max }: 4120 \pm 636 \mathrm{~Hz}\right)$. They are delivered in a cyclical, modulated pattern, similar to the chipper calls of the Chimney Swift (Chaetura pelagica; Cink and Collins 2002 ) but slower and more distinct. We observed only males performing this call, but Bird and Wright (1977) described a similar call by a female.

Scream (alarm call) (Fig. 1L). This call consists of one or two long $(2.63 \pm 0.48 \mathrm{sec})$, loud, gradually ascending and abruptly climaxing notes, sounding like a high-pitched human scream: IIIIIIIEEET! Two to three accented one-phrased hoots often follow this call. It is performed mainly by females (identifiable by the one-phrased hoots), but males have also been heard to produce this call (D. Wiens, pers. comm.).

Female begging (Fig. 1M). This is a one-note, long $(1.32 \pm$ $0.15 \mathrm{sec}$ ), thin, whistled call rising slightly in pitch (FMA: $802 \pm 32 \mathrm{~Hz} ; F_{\max }: 828 \pm 23 \mathrm{~Hz}$ ). It is eerie (Eckert 1974) and slow: errrrrrrit.

We also observed Barred Owls producing nonvocal sounds by snapping their bills (Fig. 1N). Most often, we heard bill snaps produced in a series from a solo bird, although we once heard one within a duet.

Our recordings and analyses focused on adult vocalizations, but we also heard juvenile and nestling begging calls. Juvenile and nestling begging was similar to female begging but weaker, higher-pitched, and with a raspier quality.

Vocalizations were sometimes preceded by one to three introductory notes. Introductory notes were often single, accented, notes, similar to species-typical terminal notes. Introductory notes were usually slightly higher-pitched than the following notes of the vocalization, a syncopated wooot before the remainder of the call (e.g., beginning notes in Fig. 1E and F). Introductory notes appeared to be most often performed by females in association with duets and most often preceded ascending hoots, short ascending hoots, one-phrased hoots, and sometimes gurgles.

Discriminant function analysis. Of the 13 quantitatively described vocalizations, gurgles, twitters, female begging, and screams had unique peak frequencies (Table 1) and overall structure (Fig. 1) and sounded noticeably different. We considered these distinct call types and did not include them in subsequent analyses. To evaluate whether the other vocalizations were structurally distinct, we conducted canonical discriminant analysis on two-phrased hoots, one-phrased hoots, ascending hoots, fast ascents, short ascending hoots, and inspection calls (mumbles, three-notes, and two-notes were infrequent and usually performed within duets, so we were unable to obtain a sample of nonoverlapping recordings sufficient for inclusion in our canonical discriminant analysis). Canonical discriminant function analysis based on 10 finescale measurements capably discriminated among these six call types. Vocalizations were assigned to the correct call type with $69 \%$ accuracy, well above the $17 \%$ accuracy expected by chance (chi-squared test: $\chi_{6,25}^{2}=85.0, P<0.0001$ ). There was some overlap in the $95 \%$ confidence intervals of one-phrased hoots and short ascending hoots, as well as between twophrased hoots and ascending hoots. It was misclassification of these two groups that resulted in the majority of incorrect assignments. The first canonical vector explained $88 \%$ of the variation in the original $80 \%$ of data and was correlated most strongly with call duration $(r=0.91)$, number of notes $(r=0.98)$, and duration of terminal note $(r=-0.53)$.

\section{DIEL VOCALIZATION RATES AND VOCAL BEHAVIOR}

The vocal output of Barred Owls varied significantly through the day and night (linear mixed model: $F_{9,40}=16.0, P<0.0001$; Fig. 2). Although they vocalized at all hours, owls were most vocal between 18:00 and 06:00, the hours corresponding to twilight or dark in January and early February in north Florida. Their vocal activity peaked from 02:00 to 05:00 and 18:00 to 20:00. This first peak occurred in the early morning until just before dawn and was associated mostly with an increase in inspection calls and two-phrased hoots. The second peak occurred shortly after dark and was driven by an increase in two-phrased hoots, ascending hoots, fast ascents, and duets. The most common vocalization type was inspection calls, which were given consistently throughout the night, followed by two-phrased hoots, which were most frequent between 05:00 and 20:00. Screams were given substantially less often than other vocalizations and exhibited a unique pattern, peaking around 19:00, shortly after dark. Barred Owls were least vocal between 07:00 and 14:00.

Barred Owls used different vocalizations inside versus outside of duets (log-linear regression: $F_{1,258}=151.1, P$ $<0.0001)$. Fast ascents, one-phrased hoots, three-notes, and two-notes occurred more often within duets, whereas twophrased hoots and ascending hoots occurred more often outside of duets (Table 2). Short ascending hoots occurred almost equally inside and outside of duets (Table 2). Gurgles and mumbles occurred exclusively within duets, and inspection calls, one of the most common vocalizations recorded from Barred Owls (Fig. 2), were used almost exclusively outside of duets (Table 2). 

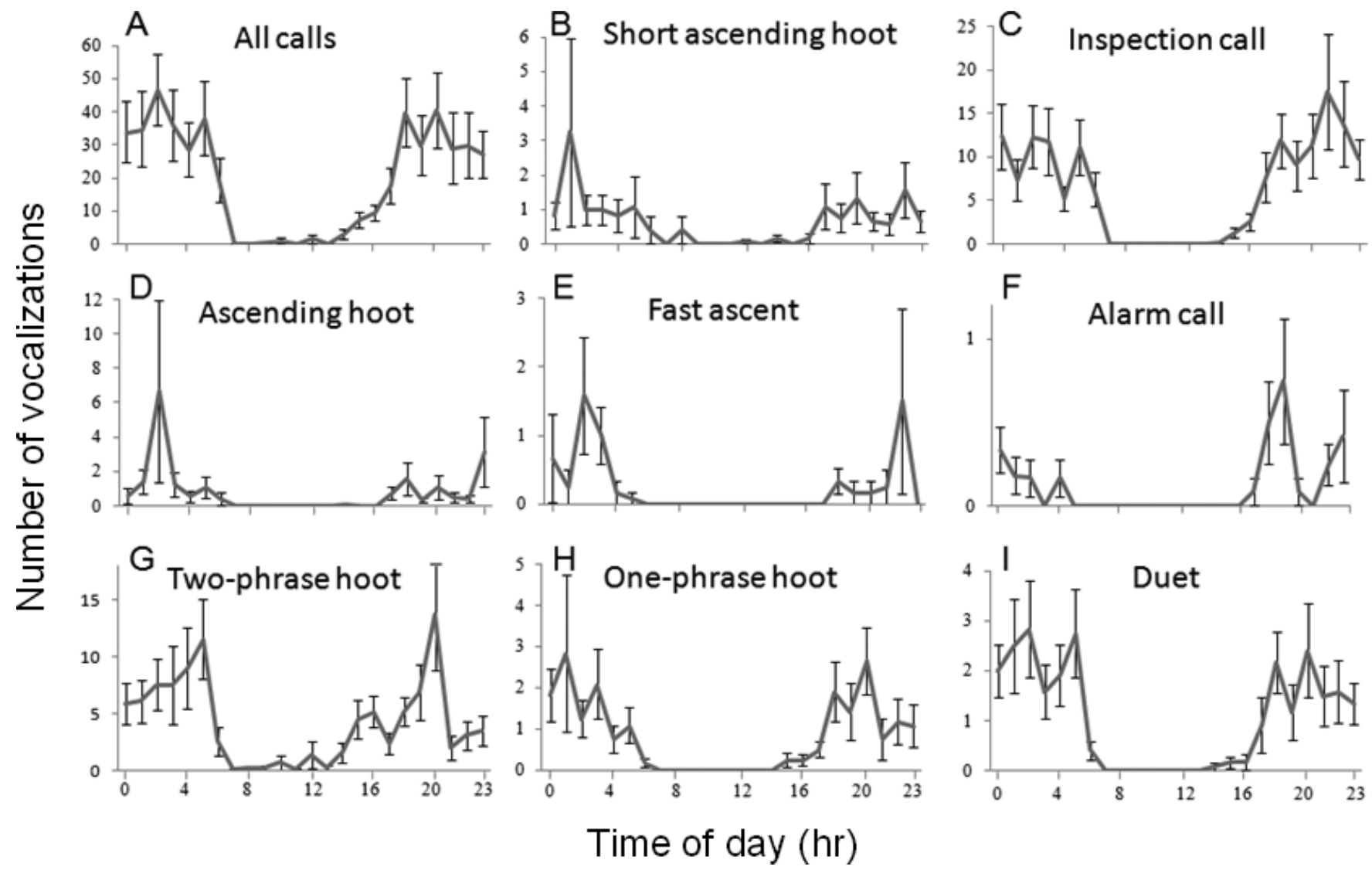

FIGURE 2. Diel variation in calling by Barred Owls, indicating rates of (A) all vocalizations combined, (B-H) seven of the most common solo vocalizations, and (I) duets.

\section{MALE-FEMALE DIFFERENCES}

Male and female Barred Owls of known sex differed substantially in maximum frequency, duration of the terminal note, and number of inflection points in the terminal note (Fig. 3, 4). Females gave higher-pitched calls than males

TABLE 2. The frequency of 10 Barred Owl vocalizations within duets versus outside of duets (based on a sample of 408 calls within duets and 408 calls outside of duets recorded at 25 different sites.)

\begin{tabular}{lcc}
\hline \hline Vocalization & Outside duet & Inside duet \\
\hline Inspection call & $142(98 \%)$ & $3(2 \%)$ \\
Two-phrased hoot & $126(80 \%)$ & $31(20 \%)$ \\
One-phrased hoot & $14(13 \%)$ & $96(87 \%)$ \\
Ascending hoot & $89(67 \%)$ & $44(33 \%)$ \\
Short ascending hoot & $29(48 \%)$ & $31(52 \%)$ \\
Fast ascent & $3(13 \%)$ & $20(87 \%)$ \\
Gurgle & $0(0 \%)$ & $161(100 \%)$ \\
Two-note & $2(20 \%)$ & $8(80 \%)$ \\
Three-note & $3(30 \%)$ & $7(70 \%)$ \\
Mumble & $0(0 \%)$ & $7(100 \%)$ \\
\hline
\end{tabular}

(Fig. 3A) and had substantially longer terminal notes (Fig. 3B) with many more inflection points (Fig. 3C).

Wild Barred Owls of unknown sex were readily separated into two groups based on hierarchical cluster analysis. A phenogram formed from the six common calls produced by both males and females grouped owls into two distinct clusters that corresponded to predicted sex with $91 \%$ accuracy. Of 86 calls predicted to be from females, 75 were assigned to a single cluster, suggesting that females could be predicted on the basis of vocalizations with $87 \%$ accuracy. Of 98 calls predicted to be from males, 92 were assigned to the second cluster, suggesting that males could be predicted based on vocalizations with $94 \%$ accuracy.

\section{DISCUSSION}

Barred Owls have a diverse vocal repertoire of over 13 different vocalizations. The calls we describe correspond to previous accounts (Brewster and Chapman 1891, Bent 1938, McGarigal and Fraser 1985), but we provide a standardized vocabulary, quantitatively verify differences between calls, and describe new vocalizations used primarily within duets. Our analyses show that structurally similar vocalizations are 

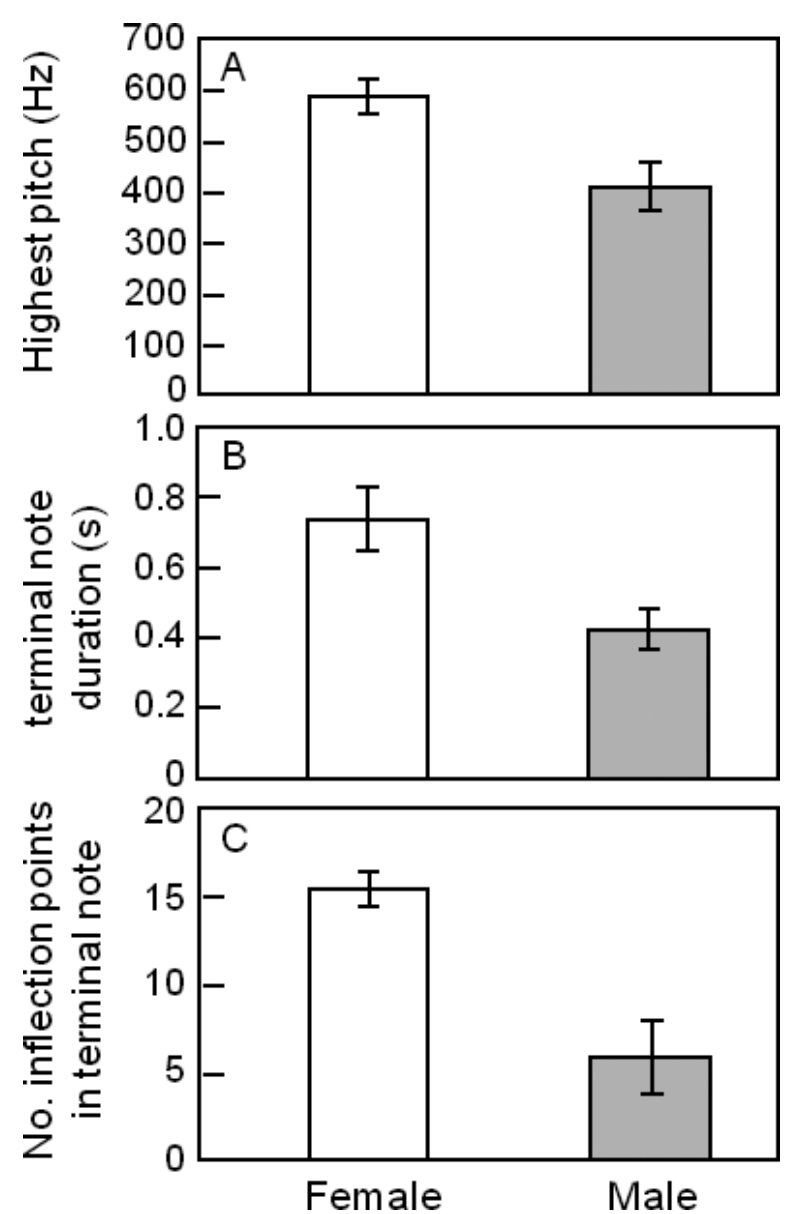

FIGURE 3. Fine-structural differences between captive Barred Owls of known sex ( $n=4$ females, 2 males), including (A) maximum frequency, (B) duration of the terminal note, and (C) number of inflection points (amount of vibrato) in the terminal note. used in separate contexts, indicated by different diel patterns and use of particular vocalizations inside versus outside of duets. We also provide some quantitative support for the idea that females' calls are higher-pitched with more elaborate terminal notes than those of males (Kroodsma 2005), although further analyses with more owls of known sex would enhance this conclusion.

The vocalizations we describe match closely with those described by Bent (1938), who described nine vocalizations included in our description in addition to duets and bill snapping. Bent's (1938) descriptions included two-phrased hoots, one-phrased hoots, gurgles, mumbles, inspection calls, screams, and female begging. Brewster and Chapman (1891) described ascending hoots and explained that this vocalization can be long or short and is sometimes delivered quickly, possibly representing ascending hoots, short ascending hoots, and fast ascents. Bent's (1938) description differs slightly from ours and includes two vocalizations we did not observe: (1) "a prolonged, tremulous call ... [with a] whining quality," phoneticized "wee-ow-o-w-ow-ow," also noted by Eckert (1974), and (2) dog-like barking. We think the former might be a description of what we identify as a twitter, but Bent's description differs substantially from ours. Other explanations include that these vocalizations are rare, products of innovation, regionally specific, or originally misidentified. McGarigal and Fraser (1985) described "an irregular and patternless assemblage of hoots." We observed Barred Owls in wildliferehabilitation centers vocalize this way when awakened and when falling to sleep. Finally, our research focused on adult vocalizations, but accounts of vocalizations of young describe hissing noises (Bent 1938, Eckert 1974) and a "ratlike squealing cry" (Eckert 1974) by nestlings and fledglings, in addition to the begging call we describe. Bird and Wright (1977)
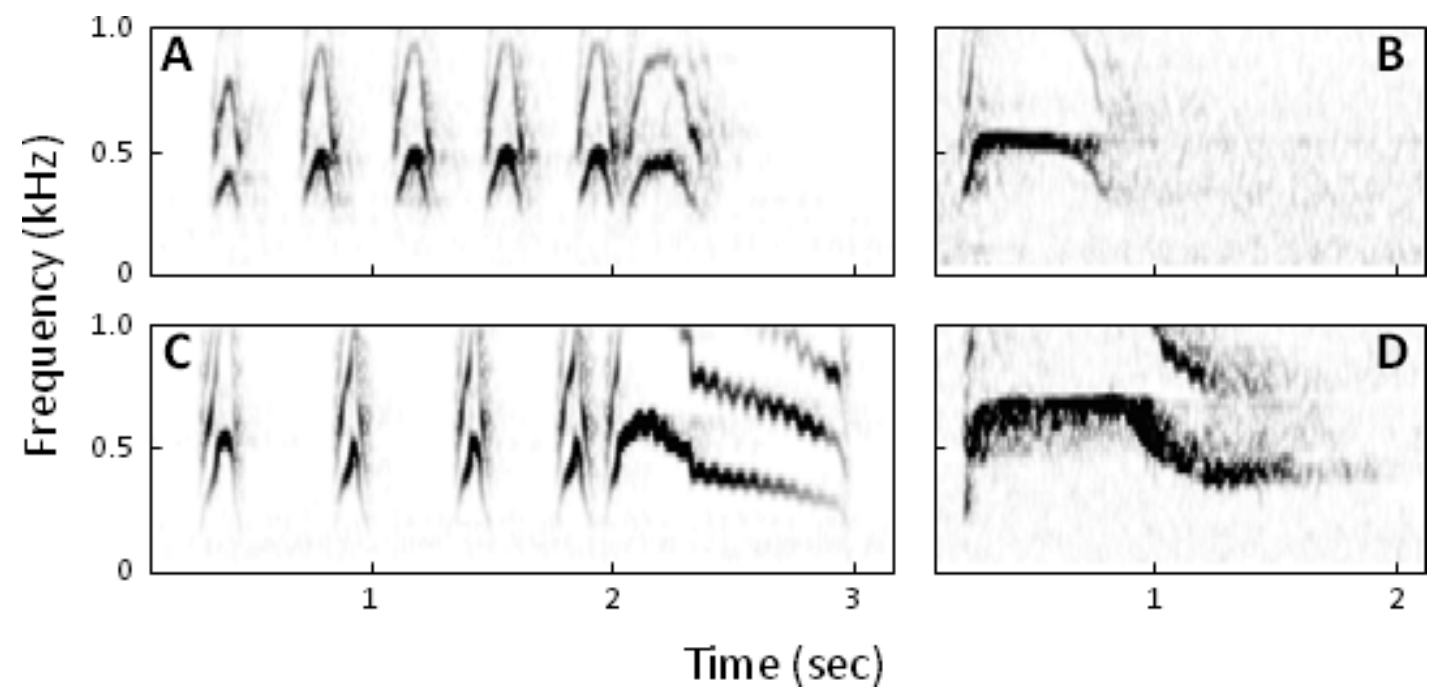

FIGURE 4. Spectrographic differences between the vocalizations of male (A and B) and female (C and D) one-phrased hoots (A and C) and inspection calls (B and D). 
described a distraction display of a female imitating vocalizations of young Barred Owls, including "chitters and squeals."

Our analyses add to what is known about Barred Owl vocalizations. We described two vocalizations not previously mentioned in the literature: the two-note and three-note calls (Fig. 1, Table 1). These vocalizations may have been overlooked because both calls are relatively uncommon, brief, and are given primarily within duets, making them difficult to detect. Using sound spectrographs to quantify vocalizations within duets also allowed us to focus on vocalizations that had been given little attention previously. Vocalizations such as gurgles, one-phrased hoots, and mumbles may have an important function within duets, but each call is only mentioned briefly in two published accounts (Brewster and Chapman 1891, Bent 1938). Additionally, we found that inspection calls are one of the most abundant vocalizations given by Barred Owls (Fig. 2), in contrast to early accounts, which give little or no recognition to this prominent vocalization (Brewster and Chapman 1891, Bent 1938). Furthermore, quantitative assessment allowed us to distinguish between similar calls, such as ascending hoots, short ascending hoots, and fast ascents. These three calls may be used in different contexts, perhaps driven by changes in motivation or intensity of the situation, such as intrusion into a territory or copulation solicitation. We noticed, specifically, that fast ascents were given most often by males at the start of a duet, while short ascending hoots are given by both sexes in the middle or toward the end of a duet (Odom and Mennill, unpubl. data). Ascending hoots were less often associated with duets. Because of these differences, it is worth considering these vocalizations separately in behavioral and bioacoustic studies.

In our discriminant analysis of call types, we found a slight overlap of $95 \%$ confidence intervals of one-phrased hoots and short ascending hoots, and of two-phrased hoots and ascending hoots. We did not predict that these vocalizations would show such similarity, and we believe the overlap resulted from the contribution of the "number of notes" variable to canonical discrimination. These two groups of vocalizations have similar numbers of notes but different intervals between notes (two-phrased hoots have a distinct gap between the fourth and fifth notes absent in ascending hoots, and onephrased hoots are syncopated, caused by a slightly longer interval after the first note; in short, ascending hoot notes are evenly spaced except for the penultimate note; see Fig. 1A and B). These vocalizations may have been more clearly separated by inclusion in the discriminant analysis of a variable expressing the ratio between the lengths of the notes and the intervals between them. Previous accounts, however, clearly define two-phrased hoots and ascending hoots as separate vocalization types (Mazur and James 2000), and we found that these vocalizations also have different patterns of diel variation and use inside and outside of duets, demonstrating that it is worthwhile to consider these as four distinct vocalizations.
Although our research did not focus explicitly on the behavioral context of individual vocalization types, our analyses of diel variation in vocal patterns and vocal activity inside and outside of duets allow us to make inferences about behavior, especially when viewed in the context of previously proposed functions and observations (Brewster and Chapman 1891, McGarigal and Fraser 1985, Johnsgard 1988). Johnsgard (1988) suggested the two-phrased hoot is the of Barred Owl's territorial call, and Brewster and Chapman (1891) observed two-phrased hoots used as a contact call. Our finding that two-phrased hoots are used throughout the night and that they routinely occur both inside and outside of duets supports the idea that the call has multiple uses. Additionally, two-phrased hoots are given often during both spontaneous bouts of vocal activity and when an owl confronts conspecifics (Odom and Mennill 2010), indicating they are important in both aggressive and nonaggressive contexts. Inspection calls are believed to be a contact call (Johnsgard 1988). Their abundance and substantial use outside of duets supports this idea. We observed inspection calls given when two birds approached one another, or a when one member of a mated pair moved away from its partner. Also, inspection calling decreased during territorial interactions (Odom and Mennill 2010). Conversely, ascending hoots increase with territory intrusion, suggesting a territorydefense function (Odom and Mennill 2010). Playback studies indicate duets also serve a territorial function, increasing with simulated territory intrusion (Odom and Mennill 2010). Therefore, vocalizations associated with duets may play a role in territory defense. However, without knowing what other functions Barred Owl duets serve, such as paternity guarding or maintaining the pair bond, we cannot claim territory defense is the primary function of all vocalizations associated with duets. For example, mumbles are performed mainly within duets but are very low in amplitude, suggesting they function within the pair rather than as a territorial signal. We suggest that the scream serves as an alarm call, supported by the unique increase in screams shortly after dark, the peak time of foraging by nocturnal mammalian nest predators (Picman and Schriml 1994). Screams have also been heard when researchers approached a nest or while the owl was being banded (D. Wiens, R. Bierregaard Jr., pers. comm.), further supporting an alarm-call function. It is important to note that our analysis of diel variation in vocal output focused on the pre-breeding season. Research on diel patterns at other times of the year could add additional information on the context and function of these vocalizations.

Our analyses show vocal differences between male and female Barred Owls. Calls of male and female captive owls of known sex differed in pitch, length of the terminal note, and amount of vibrato, as proposed by Kroodsma (2005). Females are known to produce higher-pitched vocalizations (Johnsgard 1988), and we found that longer terminal notes with more vibrato corresponded to the female's higher-pitched calls. Thus, 
all three characteristics may be useful in distinguishing between the sexes. We were also able to categorize wild owls of unknown sex into two distinct groups qualitatively and quantitatively by these features. Quantitative assignment by cluster analysis closely matched our qualitative grouping. Also, the clusters were approximately even in size, closely matching the ratio expected for a sexually determined trait. Brewster and Chapman (1891) suggested that pace of vocalizations may also differentiate the sexes. We noticed that females often give slower vocalizations, most noticeable in two-phrased, onephrased, and ascending hoots, but we did not quantify this difference. Pace may also change with motivation or context, and therefore we suggest that pitch, length of the last note, and amount of vibrato are more reliable distinguishing characteristics of sex. Because of the quantitative vocal differences we observed, we think it is important for studies examining Barred Owl vocalizations to differentiate between males and females.

Our findings have implications for future research in behavioral ecology and conservation of owls. The ability to classify an animal's vocal repertoire and distinguish males from females is important for understanding the ecology and evolution of avian vocal behavior. The Barred Owl is one of few temperate-zone species that performs vocal duets (Farabaugh 1982, Benedict 2008). Determining duet structure, the contribution of different individuals to a duet, and differences in responses of males and females to playback of a duet provides a basis for evaluating the function of duetting and whether it is motivated by cooperation or conflict (Douglas and Mennill 2010). Evaluating these components of a duet in a species from a temperate region, where duets are less common, will help elucidate the ecology and evolution of such complex vocal behaviors.

A carefully categorized description of the Barred Owl's vocal behavior provides a useful tool for surveying wild owl populations. As Barred Owls expand their range into the $\mathrm{Pa}$ cific Northwest, improved assessment of Barred Owl presence and abundance is important for Spotted Owl conservation (Buchanan et al. 2007). Identification of Barred Owls by their many different vocalizations will enhance the ability of researchers to detect this species. Distinguishing males and females by vocalizations will allow surveyors to assess presence of multiple individuals at a location and may aid in identifying breeding pairs. In addition, understanding patterns of vocal activity and context of vocalizations is important for designing effective survey methods that optimize Barred Owl detection. Broadcast of Barred Owl vocalizations may be disruptive to Spotted Owls (Crozier et al. 2006), so surveying during periods of peak calling (i.e., between 18:00 and 20:00 or 02:00 and 05:00) can increase Barred Owl detection while reducing the use of playback. Call context is also important for selecting playback stimuli that increase Barred Owl response but reduce stress to Spotted Owls. Moreover, a complete repertoire and spectrographic examples of Barred Owl vocalizations provide a standard that can be used to identify Barred Owl vocalizations in long recordings. Such information could facilitate large-scale monitoring with automated recording devices to survey passively for both species. We hope that these quantitative descriptions of Barred Owl vocalizations, sex differences, and patterns of variation in vocal behavior prove useful in designing survey protocols for the Barred Owl and facilitate future research on this species.

\section{ACKNOWLEDGMENTS}

We thank J. Stahl, T. Lee, G. Odom, B. Rolek, and G. Hill for help and organization in the field. We also thank N. Barker and J. Ciborowski for statistical guidance and E. H. Burtt Jr. for feedback on early versions of the manuscript. We are especially grateful to D. Radabaugh for his insight and guidance on initial stages of this research. We thank the Audubon Center for Birds of Prey, The Avian Reconditioning Center, Back to Nature Wildlife Refuge, Busch Wildlife Sanctuary, the Central Florida Zoo, and Tampa Lowry Park Zoo for access to their birds of prey, and everyone who discussed Barred Owl vocalizations with us. Funding was provided by the Natural Sciences and Engineering Research Council of Canada (NSERC), the Canada Foundation for Innovation, the Government of Ontario, and the University of Windsor to DJM and American Ornithologists' Union and Association of Field Ornithologists research awards to KJO. This research was also made possible, in part, by NSERC, Pelee Island Winery, Nokuse Plantation Inc. and M. C. Davis, Northwest Florida Water Management District, Florida Fish and Wildlife Conservation Commission, and the U.S. Fish and Wildlife Service in conjunction with a concurrent search for the Ivory-billed Woodpecker in north Florida.

\section{LITERATURE CITED}

Adobe Systems, InC. 2005. Adobe Audition. Version 2.0. Adobe Systems, Inc., San Jose, CA.

BENEDICT, L. 2008. Occurrence and life history correlates of vocal duetting in North American passerines. Journal of Avian Biology 39:57-65.

Bent, A. C. [ED.]. 1938. Northern Barred Owl, p. 193-194. In Life histories of North American birds of prey, Part 2. U.S. National Museum Bulletin, No.170. Dover Publications, Inc., New York, NY.

BIRD, D. M., AND J. O. WRIGHT. 1977. Apparent distraction display by a Barred Owl. Canadian Field-Naturalist 91:176-177.

Brewster, R., AND F. M. Chapman. 1891. Notes on the birds of the lower Suwanee River. Auk 8:125-138.

Buchanan, J. B., R. J. Gutiérrez, R. G. Anthony, T. Cullinan, L. V. Diller, E. D. Forsman, And A. B. Franklin. 2007. A synopsis of suggested approaches to address potential competitive interactions between Barred Owls (Strix varia) and Spotted Owls (S. occidentalis). Biological Invasions 9:679-691.

BURT, J. 2006. SYRINX-PC. Version 2.6i. University of Washington, Seattle, WA.

Cink, C. L., And C. T. Collins. 2002. Chimney Swift (Chaetura pelagica), no. 646. In A. Poole and F. Gill [EDS.], The birds of North America. Birds of North America, Inc., Philadelphia.

Crozier, M. L., M. E. Seamans, R. J. Gutiérrez, P. J. Loschl, R. B. Horn, S. G. Sovern, And E. D. Forsman. Does the presence of Barred Owls suppress the calling behavior of Spotted Owls? Condor 108:760-769.

Douglas, S. B., And D. J. MenniLl. 2010. A review of acoustic playback techniques for studying avian vocal duets. Journal of Field Ornithology 81:115-129. 
Dunstan, T., AND S. Sample. 1972. Biology of Barred Owls in Minnesota. Loon 44:111-115.

ECKerT, A. W. 1974. The Owls of North America. Doubleday, Garden City, NY.

FARABAUGH, S. M. 1982. The ecological and social significance of duetting, p. 147-208. In D. E. Kroodsma and E. H. Miller [EDS.], Acoustic communication in birds, vol. 2. Academic Press, New York.

Freeman, P. L. 2000. Identification of individual Barred Owls using spectrogram analysis and auditory cues. Journal of Raptor Research 34:85-92.

Galeotti, P., and G. Pavan. 1991. Individual recognition of male Tawny Owls (Strix aluco) using spectrograms of their territorial calls. Ethology, Ecology and Evolution 3:113-126.

Gutiérrez, R. J., M. Cody, S. Courtney, and A. B. Franklin. 2007. The invasion of Barred Owls and its potential effect on the Spotted Owl: a conservation conundrum. Biological Invasions 9:181-196.

Hill, G. E., D. J. Mennill, B. W. Rolek, T. L. Hicks and K. A SWISTON [ONLINE]. 2006. Evidence suggesting that Ivory-billed Woodpeckers (Campephilus principalis) exist in Florida. Avian Conservation and Ecology 1(3):2. http://www.ace-eco.org/vol1/ iss $3 /$ art2/ (2006).

JoHnSGARD, P. A. 1988. North American owls. Smithsonian Institution Press, Washington, DC.

Kroodsma, D. E. 2005. The singing life of birds: the art and science of listening to birdsong. Houghton Mifflin, Boston.

Mazur, K. M., AND P. C. James. 2000. Barred Owl (Strix varia), no 508. In A. Poole and F. Gill [EDS.]. The birds of North America. Birds of North America, Inc., Philadelphia.
McGarigal, K., And J. D. Fraser. 1985. Barred Owl responses to recorded vocalizations. Condor 87:552-553.

McGowan, K. J. 2001. Fish Crow (Corvas ossifragus), no. 589. In A. Poole and F. Gill [EDS.], The birds of North America. Birds of North America, Inc., Philadelphia.

Mosher, J. A., M. R. Fuller, And M. Kopeny. 1990. Surveying woodland raptors by broadcast of conspecific vocalizations. Journal of Field Ornithology 61:453-461.

OdOM, K. J., AND MenNiLl, D. J. 2010. Vocal duets in a nonpasserine: an examination of territory defense and neighbour-stranger discrimination in a neighbourhood of Barred Owls. Behaviour 147:619-639.

PiCMAn, J., AND L. M. Schriml. 1994. A camera study of temporal patterns of nest predation in different habitats. Wilson Bulletin 106:456-465.

SAS InSTITUTE. 2002. JMP. Version 5.0.1a. SAS Institute, Cary, NC. SPSS, INC. 2008. SPSS Statistics. Version 17.0. SPSS Inc., Chicago.

Syntrillium Software CoRP. 2002. Cool Edit 2000. Version 2.0. Syntrillium Software Corp., Scottsdale, AZ.

U.S. DEPARTMENT OF AGRICULTURe (USDA). 1985. Jefferson National Forest land and resource management plan. U.S. Forest Service, Roanoke, VA.

U.S. DePARTMENT OF Agriculture (USDA). 1986. Land and resource management plan Alleghany National Forest. U.S. Forest Service, Milwaukee, WI.

U.S. DePartMent of Agriculture (USDA). 1987. Land and resource management plan Chippewa National Forest. U. S. Forest Service, Milwaukee, WI. 